\title{
Src inhibition induces melanogenesis in human G361 cells
}

\author{
KYUNG-EUN KU ${ }^{1}$, NAHYUN CHOI ${ }^{1,2}$, SANG-HO OH $^{3}$, WON-SERK KIM ${ }^{4}$, \\ WONHEE SUH ${ }^{5}$ and JONG-HYUK SUNG ${ }^{1,2}$
}

\author{
${ }^{1}$ College of Pharmacy, Yonsei Institute of Pharmaceutical Sciences, Yonsei University, Incheon 21983; \\ ${ }^{2}$ STEMORE Co. Ltd., Incheon 21984; ${ }^{3}$ Department of Dermatology, Severance Hospital and \\ Cutaneous Biology Research Institute, Yonsei University College of Medicine, Seoul 03722; \\ ${ }^{4}$ Department of Dermatology, Kangbuk Samsung Hospital, Sungkyunkwan University School of Medicine, \\ Seoul 03181; ${ }^{5}$ College of Pharmacy, Chung-Ang University, Seoul 06974, Republic of Korea
}

Received July 4, 2018; Accepted February 8, 2019

DOI: $10.3892 / \mathrm{mmr} .2019 .9958$

\begin{abstract}
The Src kinase family (SKF) includes non-receptor tyrosine kinases that interact with many cellular cytosolic, nuclear and membrane proteins, and is involved in the progression of cellular transformation and oncogenic activity. However, there is little to no evidence on the effect of SKF or its inhibitors on melanogenesis. Therefore, the present study investigated whether C-terminal Src kinase inhibition can induce melanogenesis and examined the associated signaling pathways and mRNA expression of melanogenic proteins. First, whether stimulators of melanogenesis, such as ultraviolet $\mathrm{B}$ and $\alpha$-melanocyte-stimulating hormone, can dephosphorylate Src protein was evaluated, and the results revealed that SU6656 and PP2 inhibited the phosphorylation of Src in G361 cells. Src inhibition by these chemical inhibitors induced melanogenesis in G361 cells and upregulated the mRNA expression levels of melanogenesis-associated genes encoding microphthalmia-associated transcription factor, tyrosinase-related protein 1 (TRP1), TRP2, and tyrosinase. In addition, Src inhibition by small interfering RNA induced melanogenesis and upregulated the mRNA expression levels of melanogenesis-associated genes. As the p38 mitogen-activated protein kinase (MAPK) and cyclic adenosine monophosphate response element binding (CREB) pathways serve key roles in melanogenesis, the present study further examined whether
\end{abstract}

Correspondence to: Professor Jong-Hyuk Sung, College of Pharmacy, Yonsei Institute of Pharmaceutical Sciences, Yonsei University, 85 Songdogwahakro, Yeonsu-gu, Incheon 21983, Republic of Korea

E-mail: brian99@empal.com

Professor Wonhee Suh, College of Pharmacy, Chung-Ang University, 84 Heukseok-Ro, Dongjak-Gu, Seoul 06974, Republic of Korea E-mail: wsuh@cau.ac.kr

Key words: Src inhibition, melanin, G361 cell, p38, cyclic adenosine monophosphate response element binding
Src mediates melanogenesis via these pathways. As expected, Src inhibition via SU6656 or PP2 administration induced the phosphorylation of p38 or CREB, as determined by western blotting analysis, and increased the levels of phosphorylated p38 or CREB, as determined by immunofluorescence staining. In addition, the induced pigmentation and melanin content of G361 cells by Src inhibitors was significantly inhibited by p38 or CREB inhibitors. Taken together, these data indicate that $\mathrm{Src}$ is associated with melanogenesis, and Src inhibition induces melanogenesis via the MAPK and CREB pathways in G361 cells.

\section{Introduction}

Melanin is an important factor in determining the color of the human skin, hair and eyes $(1,2)$. It is produced in the melanosome through a complex process known as melanogenesis (3-5). In addition, melanin serves an important role in photoprotection from ultraviolet (UV) radiation and external stress $(1,3)$. Growth factors, cytokines, hormones and other receptor ligands exert their function by interacting with their receptors on the cell surface, generating a signaling cascade and leading to distinct patterns of protein phosphorylation. Melanocytes express several distinct receptor tyrosine kinases (RTKs) that bind bone morphogenic protein (BMP), hepatocyte growth factor (HGF) and c-Kit ligand. For example, BMP-2 stimulates tyrosinase gene expression and melanogenesis in differentiated melanocytes, and BMP signaling controls hair pigmentation via cross-talk with the melanocortin receptor-1 pathway (6). The activation of Met in response to HGF acts as a mitogen for melanocytes and synergistically contributes to malignant progression with the aberrant expression of basic fibroblast growth factor in malignant melanocytes (7). Normal human melanocytes and melanoma cells express the c-Kit gene and stem cell factor (SCF), a ligand of the c-Kit receptor that upregulates the expression of melanogenic proteins (8). In addition, $\mathrm{SCF} / \mathrm{c}-\mathrm{Kit}$ signaling is required for cyclic regeneration of the hair pigmentation unit (9). Phosphorylation of these RTKs subsequently activates a series of kinases known as mitogen-activated protein kinases (MAPKs) or other intracellular signaling molecules such as cyclic 
adenosine monophosphate (10). Then, following the phosphorylation of proteins such as microphthalmia-associated transcription factor (MITF), the transcription of genes that participate in melanocyte proliferation and melanogenesis is activated (11).

The Src kinase family (SKF) is a family of non-receptor tyrosine kinases that is composed of nine members including Src, Yes and Fyn. SKF interacts with many cellular cytosolic, nuclear and membrane proteins, modifying these proteins by phosphorylating tyrosine residues and contributing to the progression of cellular transformation and oncogenic activity (12). Of these, C-terminal Src kinase (c-Src) is encoded by the SRC gene in humans; it phosphorylates specific tyrosine residues in other proteins. c-Src can be activated by many transmembrane proteins including RTKs, such as platelet-derived growth factor receptor, epidermal growth factor receptor, and c-Kit. Therefore, c-Src is closely associated with the RTK pathways (13). As RTKs serve a critical role in the development and progression of many types of cancer (12), an elevated activity level of c-Src tyrosine kinase is associated with the progression of different types of cancers, such as pancreatic and breast cancers (14). Therefore, diverse Src inhibitors have been developed to prevent cancer progression, and drugs against RTKs are widely used in cancer therapy. However, there is little to no evidence on the effects of SKF or its inhibitors on melanocytes. Therefore, the present study investigated the effect of a c-Src inhibitor on melanocytes and its associated signaling pathways.

\section{Materials and methods}

Cell cultures and chemical treatment. Human G361 melanoma cells (cat. no. ATCC ${ }^{\circledR}$ CRL-1424 ${ }^{\mathrm{TM}}$; American Type Culture Collection, Manassas, VA, USA) were cultured in low glucose Dulbecco's modified Eagle's medium with $10 \%$ fetal bovine serum (FBS; Gibco; Thermo Fisher Scientific, Inc., Waltham, MA, USA) and $1 \%$ penicillin/streptomycin (Gibco; Thermo Fisher Scientific, Inc.). G361 cells were maintained at $37^{\circ} \mathrm{C}$ in a humidified $5 \% \mathrm{CO}_{2}$ incubator. $\alpha$-Melanocyte-stimulating hormone ( $\alpha$-MSH; Sigma-Aldrich; Merck KGaA, Darmstadt, Germany), SU6656 (cat. no. S7774; Selleck Chemicals, Houston, TX, USA), PP2 (cat. no. S7008; Selleck Chemicals), H-89 [protein kinase A (PKA) inhibitor; cat. no. B1427; Sigma-Aldrich; Merck KGaA], SB203580 (p38 inhibitor; cat. no. S8307; Sigma-Aldrich; Merck KGaA) dasatinib (cat. no. CDS023389; Sigma-Aldrich; Merck KGaA) and nilotinib (cat. no. CDS023093; Sigma-Aldrich; Merck KGaA) were utilized in the present study. For these chemical treatments in all of the experiments, $1 \times 10^{5}$ cells were seeded in a 6 -well plate for 2 days at $37^{\circ} \mathrm{C}$ with normal medium including $10 \%$ FBS and $1 \%$ penicillin/streptomycin and were changed with normal media, which included the aforementioned chemicals. All cells, except those used for western blotting and siRNA transfection experiments, were incubated for 9 days following chemical treatments at $37^{\circ} \mathrm{C}$. For western blotting, $\alpha$-MSH treated cells were harvested at $0,5,15$ and $30 \mathrm{~min}$. SU6656 or PP2 treated cells were harvested at $0,5,15,30,60$ or $120 \mathrm{~min}$. For melanin content measurement, cells were treated with $\alpha$-MSH $(1 \mu \mathrm{M})$, dasatinib and nilotinib (both at $0.1 \mathrm{M}$ ) for 0 , 3,6 , and 9 days, and then cells were harvested. Cells were treated with SU6656 and PP2 at different doses $(1,10,100$ and $1000 \mathrm{nM}$ ) and harvested 9 days later.

Drug solution preparation. All chemical concentrations employed in the present study were presented as stock/working concentrations as follows; $\alpha-\mathrm{MSH}$ was used at $200 \mu \mathrm{M} / 1 \mu \mathrm{M}$, and SU6656 and PP2 were used as $0.2 \mu \mathrm{M} / 1 \mathrm{nM}, 2 \mu \mathrm{M} / 10 \mathrm{nM}$, $20 \mu \mathrm{M} / 100 \mathrm{nM}$ and $200 \mu \mathrm{M} / 1,000 \mathrm{nM}$. The p38 inhibitor SB203580 was used at $400 \mu \mathrm{M} / 1 \mu \mathrm{M}$, and the final concentration of the $\mathrm{p} 38$ inhibitor was $8 \mathrm{mM} / 20 \mu \mathrm{M}$. The PKA inhibitor H-89 was used $1 \mathrm{mM} / 1 \mu \mathrm{M}$. Dasatinib and nilotinib were used at $10 \mathrm{M} / 0.1 \mathrm{M}$.

UV irradiation. A total of $1 \times 10^{5}$ cells were seeded in plates and incubated at $37^{\circ} \mathrm{C}$ for $48 \mathrm{~h}$. They were washed with phosphate-buffered saline (PBS) and covered with a thin layer of PBS prior to UV exposure. The culture plate lid was removed and cells were irradiated (UVB: $5 \mathrm{~mJ} / \mathrm{cm}^{2}$ ) in a dark box. The UVB irradiation apparatus (BLE-1T158) was obtained from Spectronics Corporation (Westbury, NY, USA). The incident dose of UVB was measured using a Waldmann UV meter (model no. 585100; Herbert Waldmann GmbH \& Co. KG, Villingen-Schwenningen, Germany). Following UV irradiation, PBS was replaced with culture medium at $37^{\circ} \mathrm{C}$. The irradiated cells were harvested at $0,1,5$ and $10 \mathrm{~min}$ following UV irradiation for western blotting. For melanin content measurements, the irradiated cells were also harvested at $0,3,6$ and 9 days.

siRNA transfection. G361 cells were seeded in 60-mm dishes at $1 \times 10^{5}$ cells, and Src siRNA or negative control siRNA were transfected using Lipofectamine ${ }^{\mathrm{TM}}$ RNAiMAX (Invitrogen; Thermo Fisher Scientific, Inc.). The sequences of Src siRNA (Bioneer Corporation, Daejeon, Korea; cat \#100545; stock concentration $100 \mathrm{nM}$ /working concentration 10 or $20 \mathrm{nM}$ ) was as follows: Sense, GUGUCUUAAUACUGUCCUU(dTdT) and antisense, AAGGACAGUAUUAAGACAC(dTdT). The sequence of the negative control siRNA is commercially unavailable (cat. no. SN-1002; Bioneer Corporation). G361 cells were harvested following 6 days and mRNA expression levels were analyzed via reverse transcription-quantitative polymerase chain reaction (RT-qPCR). Transfection efficiency of siRNA was evaluated by qPCR.

Observation of cell pellets and measuring the melanin content. To measure the melanin content, cells were seeded in $60-\mathrm{mm}$ dishes at $1 \times 10^{5}$ cells/dish, incubated at $37^{\circ} \mathrm{C}$ for 2 days and treated at $37^{\circ} \mathrm{C}$ with SU6656, PP2, $\alpha$-MSH, p38 inhibitor, PKA inhibitor, Src siRNA (cat. no. 100545), dasatinib and nilotinib for 9 days. SU6656 and PP2 were used at 0,1,10, 100 and $1,000 \mathrm{nM}$, and $\alpha$-MSH was used at $1 \mu \mathrm{M}$. The $\mathrm{p} 38$ inhibitor (SB203580) was used at $20 \mu \mathrm{M}$, PKA inhibitor (H-89) was used at $1 \mu \mathrm{M}$ and Src siRNA was used at $20 \mathrm{nM}$. Dasatinib and nilotinib were used at $0.1 \mathrm{M}$ (data not shown). Cells were trypsinized using $0.25 \%$ trypsin, harvested by centrifugation at $13,000 \mathrm{x}$ g for $1.5 \mathrm{~min}$ at $4^{\circ} \mathrm{C}$, photographed and solubilized in boiled $1 \mathrm{~N} \mathrm{NaOH}\left(80^{\circ} \mathrm{C}\right)$ for $2 \mathrm{~h}$; the absorbance was then measured at $405 \mathrm{~nm}$, as described previously (15). Measurement of melanin contents following UVB irradiation was also conducted in the same manner. The amount of 
melanin measured in all experiments was normalized to the relative value of the control group.

RNA extraction, RT-qPCR and semi-quantitative (sq)-PCR analysis. Total RNA was extracted from G361 cells using Favor-Prep ${ }^{\mathrm{TM}}$ Blood/Cultured cell total RNA purification mini kit (Favorgen Biotech Corp., Ping-Tung, Taiwan) and subjected to cDNA synthesis using oligodT and the HelixCript ${ }^{\mathrm{TM}}$ Thermo Reverse Transcription System (NanoHelix Co., Ltd., Daejeon, Korea) according to the manufacturer's instructions. qPCR amplification of cDNA was performed in a total volume of $30 \mu \mathrm{l}$ under the following thermocycling conditions: Initial denaturation at $95^{\circ} \mathrm{C}$ for $5 \mathrm{~min}$, followed by 27 cycles of $95^{\circ} \mathrm{C}$ for $30 \mathrm{sec}, 54^{\circ} \mathrm{C}$ for $20 \mathrm{sec}$ and $72^{\circ} \mathrm{C}$ for $30 \mathrm{sec}$, and a final extension at $72^{\circ} \mathrm{C}$ for $10 \mathrm{~min}$. For the qPCR reaction, BrightGreen qPCR master mix-ROX (Abcam, Cambridge, MA, USA) was used and reaction was carried out using Applied biosystems qPCR Machine; quantification was conducted using the $2^{-\Delta \Delta C q}$ method (16). The GAPDH mRNA expression level was used for sample standardization. For the quantification of sqPCR data, the amplification conditions of all genes were $95^{\circ} \mathrm{C}$ for $5 \mathrm{~min}$, followed by 40 cycles of $95^{\circ} \mathrm{C}$ for $1 \mathrm{~min}, 55^{\circ} \mathrm{C}$ for $1 \mathrm{~min}$ and $72^{\circ} \mathrm{C}$ for $1 \mathrm{~min}$, and then a final extension at $72^{\circ} \mathrm{C}$ for $10 \mathrm{~min}$. Then the samples were loaded onto $1.5 \%$ agarose gel containing GelRed and electrophoresed. The bands were visualized using a UV illuminator. The band intensity of the product was calculated using ImageJ (version 1.45; National Institutes of Health, Bethesda, MD, USA) (17). For RT-PCR the primers used were as follows: MITF forward, 5'-TGC CCAGGCATGAACACAC-3', and reverse, 5'-TGGGAAAAA TACACGCTGTGAG-3'; tyrosinase-related protein 1 (TRP1) forward, 5'-TCTCTGGGCTGTATCTTCTTCC-3' and reverse, 5'-GTCTGGGCAACACATACCACT-3'; TRP2 forward, 5'-CTTGGGCTGCAAAATCCTGC-3' and reverse 5'-CAG CACTCCTTGTTCACTAGG-3'; tyrosinase forward, 5'-TGC ACAGAGAGACGACTCTTG-3' and reverse 5'-GAGCTG ATGGTATGCTTTGCTAA-3'; GAPDH forward, 5'-GGA GCGAGATCCCTCCAAAAT-3' and reverse, 5'-GGCTGT TGTCATACTTCTCATGG-3'.

Western blotting. For western blotting, $1 \times 10^{5}$ cells were treated with SU6656 $(1 \mu \mathrm{M})$, PP2 $(1 \mu \mathrm{M})$ or $\alpha$-MSH $(1 \mu \mathrm{M})$ for 9 days and then lysed with protein extraction solution (PRO-PREP ${ }^{\mathrm{TM}}$; Intron Biotechnology, Inc., Seongnam, Korea). Protein quantification was performed using a Bicinchoninic Acid (BCA) assay kit (Pierce ${ }^{\mathrm{TM}}$ BCA Protein Assay kit; Thermo Fisher Scientific, Inc.). A total of $70 \mu \mathrm{g}$ of protein was loaded in a $12 \%$ acrylamide gel and run for $1.5 \mathrm{~h}$; all protein was then transferred to a PVDF membrane (Immobilon-P; Merck KGaA). The transferred membrane was blocked with $5 \%$ bovine serum albumin (BSA; Bovogen; Bovogen Biologicals Pty Ltd., Keilor East VIC, Australia) blocking buffer for $1 \mathrm{~h}$ at room temperature, incubated with primary antibodies $(1: 1,000)$ overnight at $4^{\circ} \mathrm{C}$, washed with PBS several times and then incubated with secondary antibodies $(1: 2,000)$ at room temperature for $1 \mathrm{~h}$. The primary antibodies used were as follows: Rabbit phosphorylated (phospho)-Src (cat. no. \#6943; Cell Signaling Technology, Inc., Danvers, MA, USA), rabbit Src (cat. no. 2123; Cell Signaling Technology, Inc.), mouse phospho-p38 (cat. no. 9216; Cell Signaling Technology, Inc.), rabbit p38 (cat. no. 9212; Cell Signaling Technology, Inc.), rabbit phospho-cyclic adenosine monophosphate response element binding (CREB; cat. no. 9198; Cell Signaling Technology, Inc.), rabbit CREB (cat. no. 9197; Cell Signaling Technology, Inc.), mouse $\beta$-actin (cat. no. sc-1615; Santa Cruz Biotechnology, Inc., Dallas, TX, USA) and mouse $\alpha$-tubulin (cat. no. sc-32293; Santa Cruz Biotechnology, Inc.). The secondary antibodies used were as follows: Peroxidase labeled anti-mouse immunoglobulin (Ig)-G (cat. no. PI-2000; Vector Laboratories, Inc.; Maravai LifeSciences, San Diego, CA, USA) and peroxidase labeled anti-rabbit IgG (cat. no. PI-1000; Vector Laboratories, Inc.; Maravai LifeSciences). Following the addition of Enhanced Chemiluminescence solution (Immobilon Western; Merck KGaA), western blotting images were obtained using ImageQuant LAS 4000 (GE Healthcare Bio-Sciences, Pittsburgh, PA, USA). Band densities were quantified using ImageJ software (version 1.45; National Institutes of Health, Bethesda, MD, USA). The quantification of the phosphorylated protein was calculated as follows: (p-protein/internal control)/(total protein/internal control).

Immunofluorescence. For immunofluorescence staining, $1 \times 10^{5}$ cells were fixed with $4 \%$ paraformaldehyde for $30 \mathrm{~min}$ at room temperature, rinsed in PBS, blocked in $5 \%$ BSA-containing TBS-Tx (supplemented with $0.2 \%$ Triton-X-100) for $1.5 \mathrm{~h}$ at room temperature and incubated with the primary antibodies overnight at $4{ }^{\circ} \mathrm{C}$. The primary antibodies used were anti-mouse phospho (p)-p38 (1:200; cat. no. 9216; Cell Signaling Technology, Inc.) and anti-rabbit p-CREB (1:200; cat. no. 9198; Cell Signaling Technology, Inc.). Then, cells were incubated with the secondary antibodies, Alexa Fluor 488 goat anti-mouse IgG (cat. no. A11001; Invitrogen; Thermo Fisher Scientific, Inc.) and Alexa Fluor 488 goat anti-rabbit IgG (cat. no. A11008; Invitrogen; Thermo Fisher Scientific, Inc.) with 4,6-diamidino-2-phenylindole (Sigma-Aldrich; Merck KGaA) for $1 \mathrm{~h}$ at room temperature. Immunofluorescence staining was imaged using a ZEISS LSM700 confocal microscope (magnification, x40).

Statistical analysis. Data are presented as the mean \pm standard deviation of three independent experiments. Student's t-test was used between two groups and one-way analysis of variance with Tukey's post hoc test were used for comparing multiple groups. $\mathrm{P}<0.05$ was considered to indicate a statistically significant difference. All statistical analyses were conducted using GraphPad Prism 5.01 (GraphPad Software, Inc., La Jolla, CA, USA).

\section{Results}

$U V B$ and $\alpha-M S H$ decrease the phosphorylation of Src protein in $G 361$ cells. UVB radiation is a physical stimulus that increases the amount of melanin produced in human melanoma cells. $\alpha-\mathrm{MSH}$ is also known to increase melanin production in human melanoma cells (18). The present study treated G361 cells with $5 \mathrm{~mJ}$ of UVB and $1 \mu \mathrm{M}$ of $\alpha-\mathrm{MSH}$, which are both known stimulants of melanogenesis. As a result, the phosphorylation of Src protein was decreased by melanin-stimulation (Fig. 1A and B). It was also confirmed that these melanin stimulants increased melanin production 
A

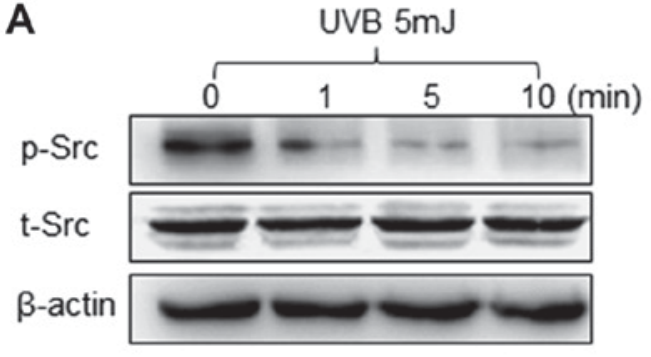

B
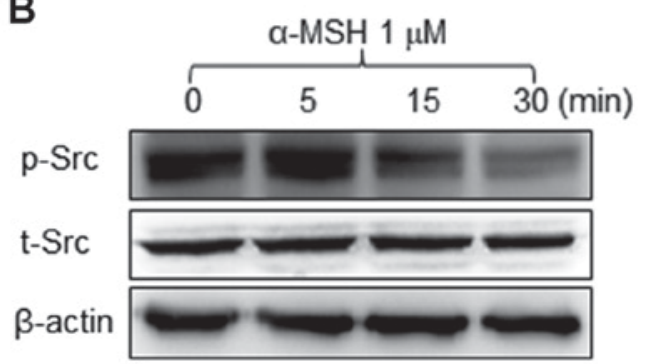

C

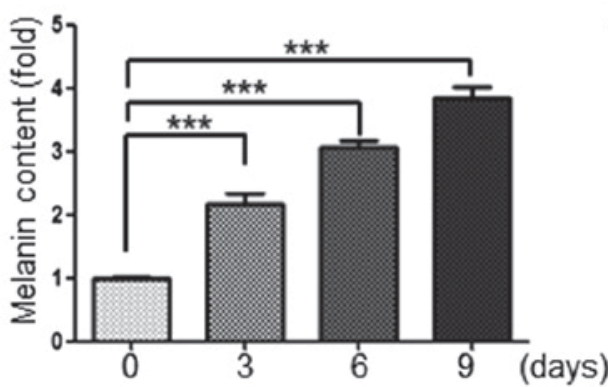

E

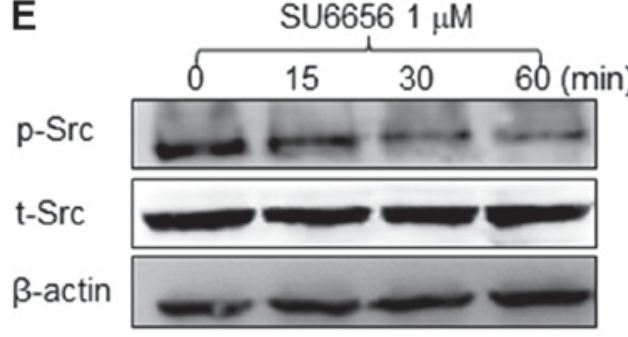

F

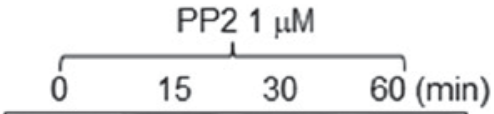

p-Src

t-Src

$\beta$-actin
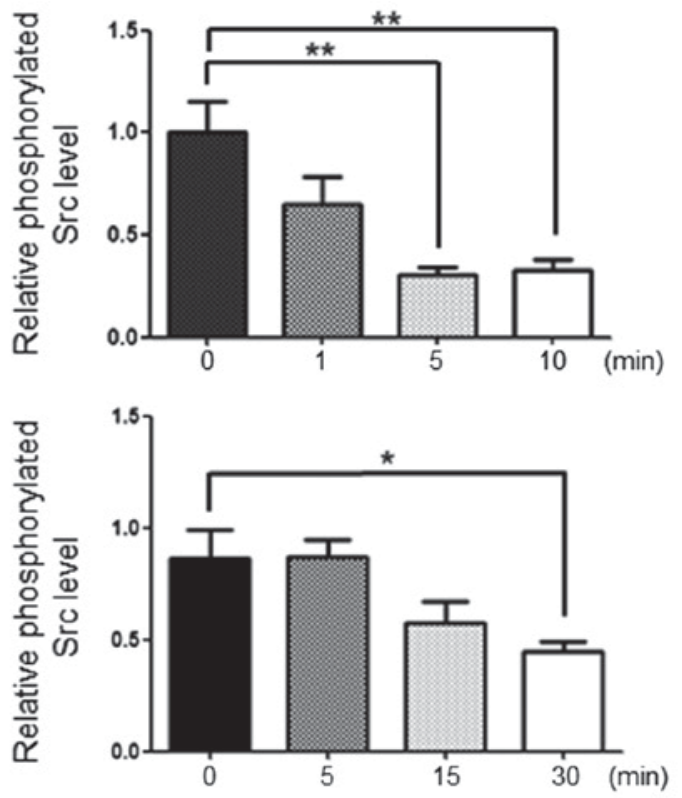

D
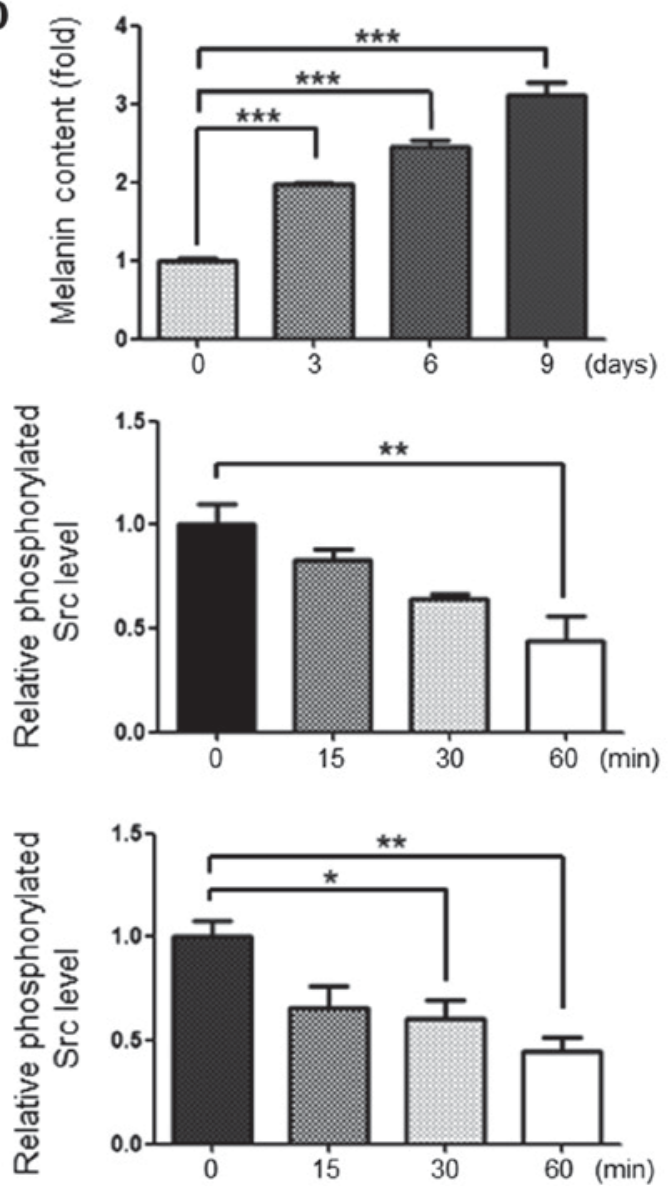

Figure 1. Inhibition of Src phosphorylation by UVB or $\alpha$-MSH. The stimulators of melanogenesis, (A) UVB and (B) $\alpha$-MSH, inhibited the phosphorylation of Src in G361 cells. (C) UVB and (D) $\alpha$-MSH promoted melanin synthesis. In addition, the Src inhibitors, (E) SU6656 and (F) PP2 reduced the levels of p-Src protein. Data are presented as the mean \pm standard deviation $(n=3) .{ }^{*} \mathrm{P}<0.05,{ }^{* *} \mathrm{P}<0.01$ and ${ }^{* * * *} \mathrm{P}<0.001$, as indicated. p-Src, phosphorylated Src; t-Src; total Src; UVB, ultraviolet B; $\alpha$-MSH, $\alpha$-melanocyte-stimulating hormone.

in a time-dependent manner (Fig. 1C and D) Therefore, it was hypothesized that Src inhibition may be required for melanogenesis in $\mathrm{G} 361$ cells. The present study also used $1 \mu \mathrm{M}$ of the Src inhibitors SU6656 and PP2 to inhibit the phosphorylation of Src protein (Fig. 1E and F).
SU6656 and PP2 induce melanogenesis in G361 cells. Up to $1,000 \mathrm{nM}$ of SU6656 and PP2 were used to treat G361 cells as these inhibitors are toxic at high concentrations. Following SU6656 treatment, the pellet color of G361 cells became darker in a concentration-dependent manner (Fig. 2A). In 
A
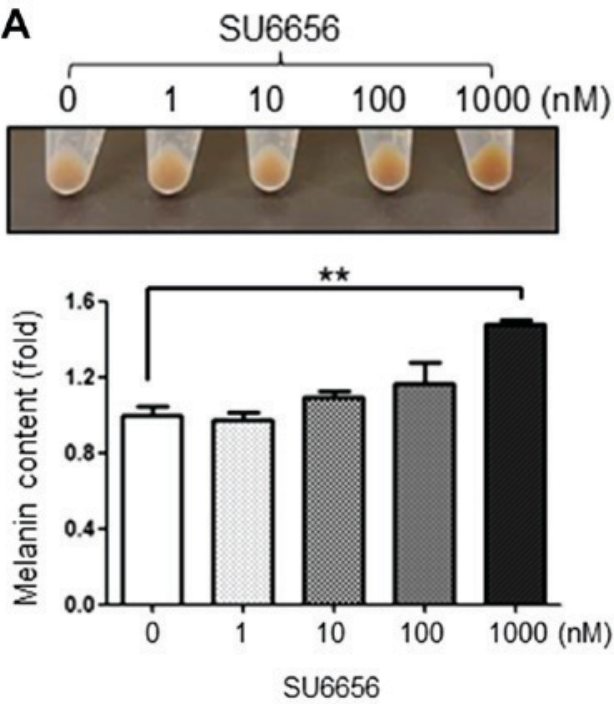

B
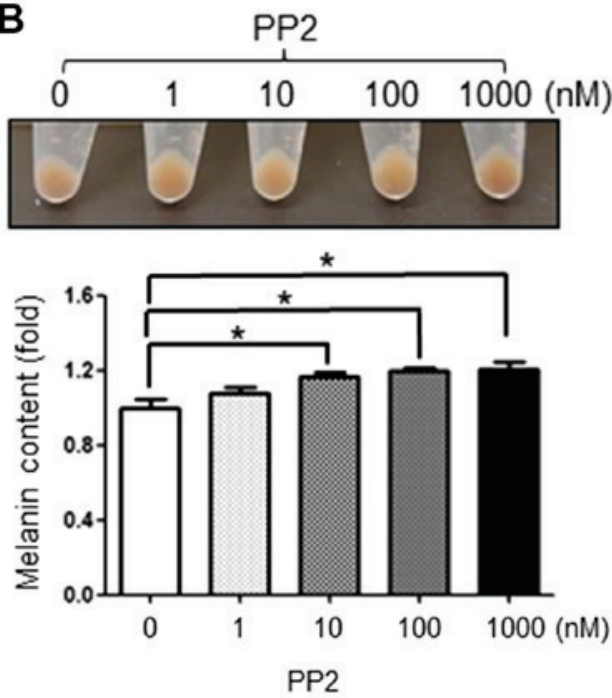

Figure 2. Src inhibitors induce melanogenesis in a dose-dependent manner. (A) SU6656 and (B) PP2 increases pellet pigmentation and melanin content in a dose-dependent manner. Data are presented as the mean \pm standard deviation $(\mathrm{n}=3)$. ${ }^{*} \mathrm{P}<0.05$ and ${ }^{* * *} \mathrm{P}<0.01$, as indicated.

A

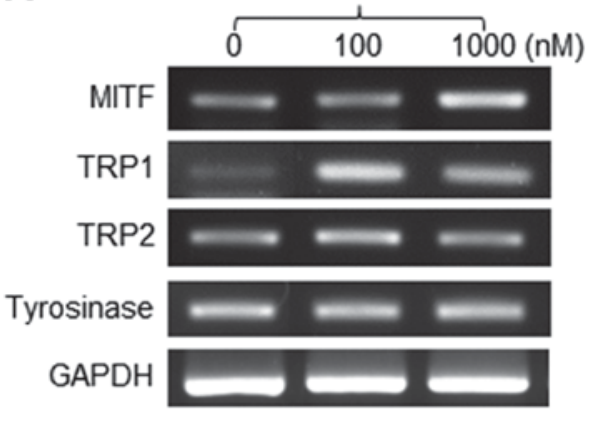

B

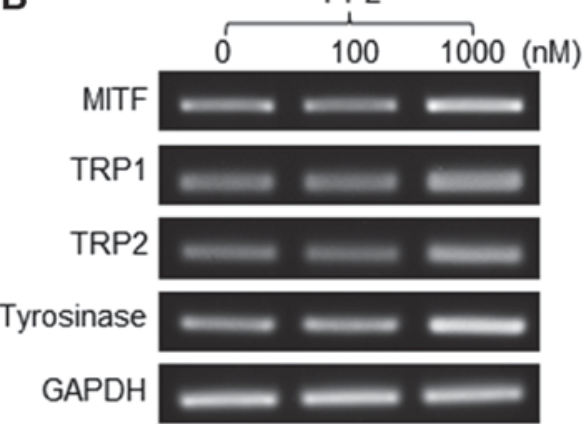

SU6656

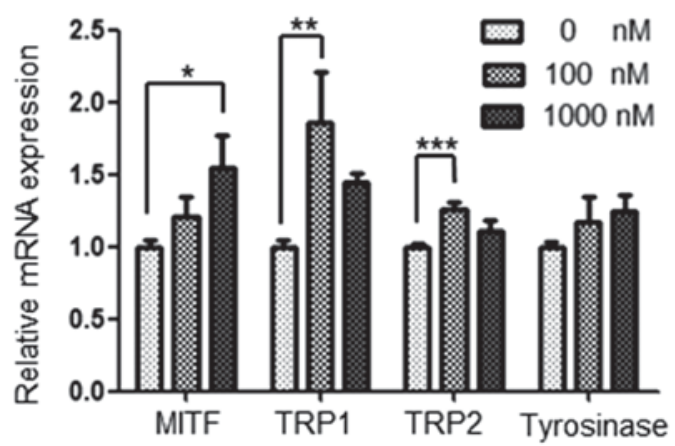

PP2

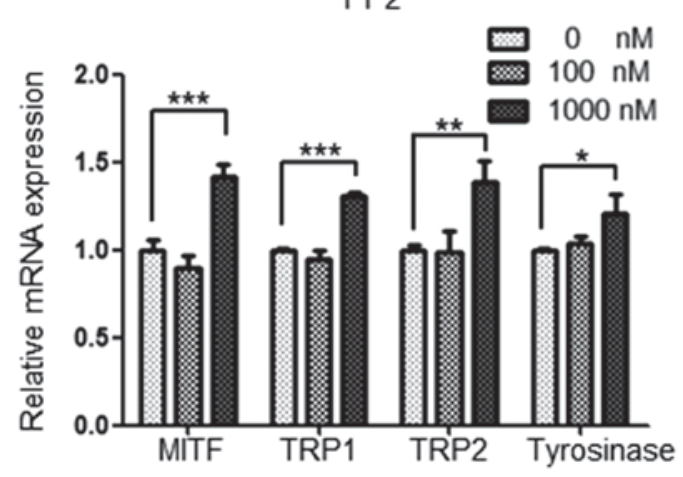

Figure 3. Upregulation of melanogenesis-associated genes by Src inhibitors. Relative mRNA expression levels of the melanogenesis-associated genes MITF, TRP1, TRP2 and tyrosinase were examined by (A) SU6656 or (B) PP2 in G361 cells, and mRNA expression was induced by Src inhibitors. Data are presented as the mean \pm standard deviation $(\mathrm{n}=3) .{ }^{*} \mathrm{P}<0.05,{ }^{* *} \mathrm{P}<0.01$ and ${ }^{* * *} \mathrm{P}<0.001$, as indicated. MITF, microphthalmia-associated transcription factor; TRP, tyrosinase-related protein.

addition, PP2 also increased the melanin content in G361 cells in a dose-dependent manner (Fig. 2B).

SU6656 and PP2 regulate the $m R N A$ expression levels of melanogenesis-associated genes. As MITF, TRP1, TRP2 and tyrosinase are key factors in mediating melanogenesis, the present study investigated whether Src inhibitors upregulated the mRNA expression of these genes. As expected, treatment with 100 and $1,000 \mathrm{nM}$ of SU6656 for 9 days upregulated the mRNA expression of melanogenesis-associated genes in G361 cells. In particular, the expression of MITF and TRP1 were upregulated by up to 55 and $87 \%$, respectively (Fig. 3A). In addition, PP2 upregulated the mRNA expression of MITF, TRP1, TRP2 and tyrosinase at 1,000 nM (Fig. 3B). 
A
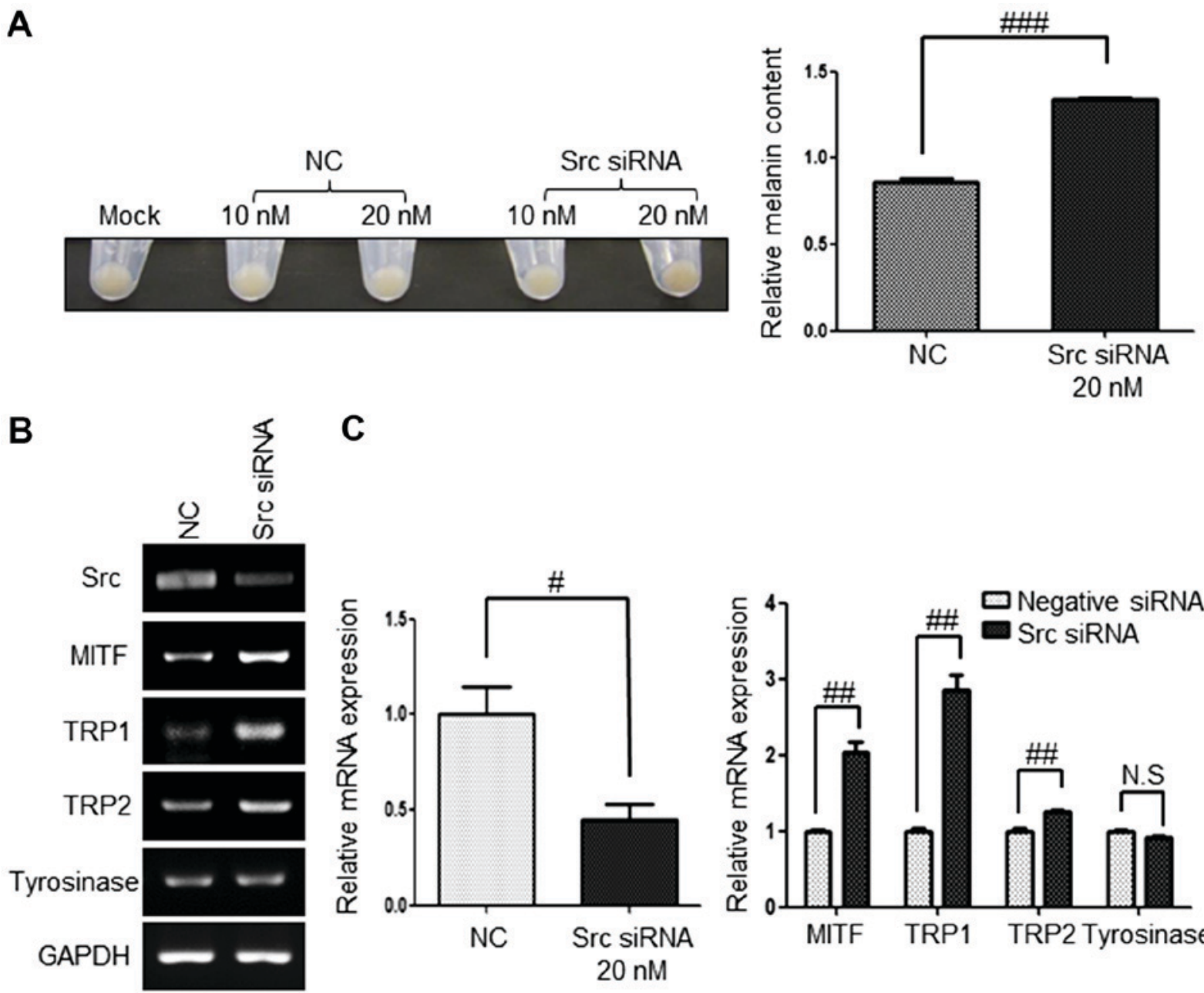

\section{C}
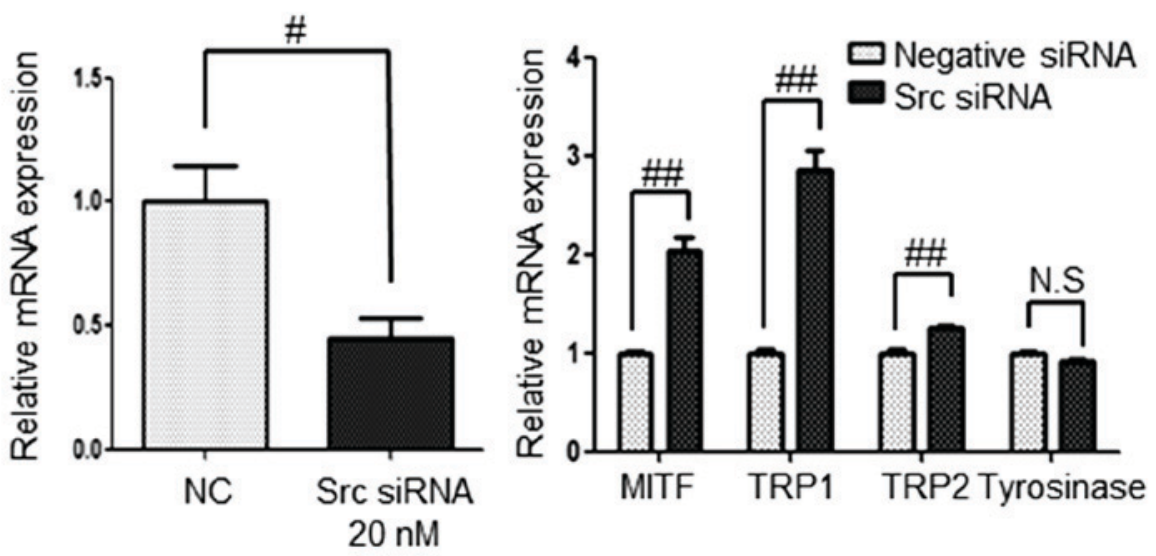

Figure 4. Src inhibition by Src siRNA induces melanogenesis and upregulates melanogenesis-associated genes. (A) Increase in pigmentation by $20 \mathrm{nM}$ Src siRNA treatment. (B and C) Upregulated mRNA expression levels of melanogenesis-associated genes induced by $20 \mathrm{nM}$ Src siRNA; as determined by (B) semi-quantitative PCR and (C) reverse transcription-quantitative PCR. Data are presented as the mean \pm standard deviation ( $\mathrm{n}=3$ ). ${ }^{\#} \mathrm{P}<0.05$, ${ }^{\# \#} \mathrm{P}<0.01$ and

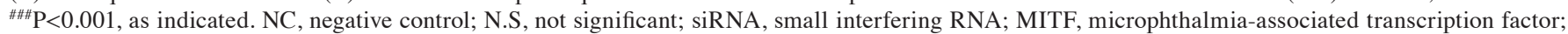
TRP, tyrosinase-related protein; PCR, polymerase chain reaction.

Src inhibition by siRNA upregulates the expression of melanogenesis-associated genes. To further determine whether melanogenesis is specifically due to Src inhibition in G361 cells, the present study examined the pellet color, melanin contents and expression of melanogenesis-association genes following the inhibition of Src using Src siRNA. G361 cells were harvested 6 days post-transfection with $20 \mathrm{nM}$ of Src siRNA. Src inhibition using Src siRNA produced a darker pellet color than the negative control (Fig. 4A) and the Src mRNA level was downregulated effectively with $\sim 60 \%$ efficiency (Fig. 4B and C). The mRNA expression levels of the melanogenesis-associated genes MITF, TRP1, TRP2 and tyrosinase were examined by RT-qPCR and sqPCR. The mRNA expression of MITF and TRP1 in Src knockdown cells was significantly upregulated by 2- and 2.8-fold, respectively. In addition, the expression of TRP 2 in Src knockdown cells was upregulated when compared with that of the control (Fig. 4B and C). However, the mRNA expression level of tyrosinase was not altered by Src siRNA.

SU6656 and PP2 induce p38 and CREB activation in G361 cells. The phosphorylation of $\mathrm{p} 38$ and CREB reportedly serves a key role in melanogenesis (19). Therefore, the present study investigated whether Src inhibitors affect the phosphorylation of p38 and CREB by time course via western blot analysis. When G361 cells were treated with $1 \mu \mathrm{M}$ of SU6656, the phosphorylation of p38 and CREB was increased over time as determined by western blot analysis (Fig. 5A). Similarly, $1 \mu \mathrm{M}$ of PP2 increased the phosphorylation of p38 and CREB over time as determined by western blot analysis (Fig. 5B). Src inhibition by SU6656 or PP2 also increased the protein levels of phosphorylated p38 and CREB, as presented by immunofluorescence staining (Fig. 5C).

Inhibition of p38 and CREB abolishes the increase in melanogenesis induced by SU6656 and PP2. As Src inhibitors activate the p38 MAPK signaling pathways and the phosphorylation of CREB (19), the present study investigated whether inhibition of these signaling pathways attenuated the increased melanogenesis induced by SU6656 and PP2. As expected, the p38 inhibitor, SB203580 $(20 \mu \mathrm{M})$, significantly attenuated the increased melanogenesis induced by the Src inhibitors SU6656 and PP2. At the same time, it was confirmed that the activation of p38 was also markedly reduced (Fig. 6A and B). Similarly, 
A

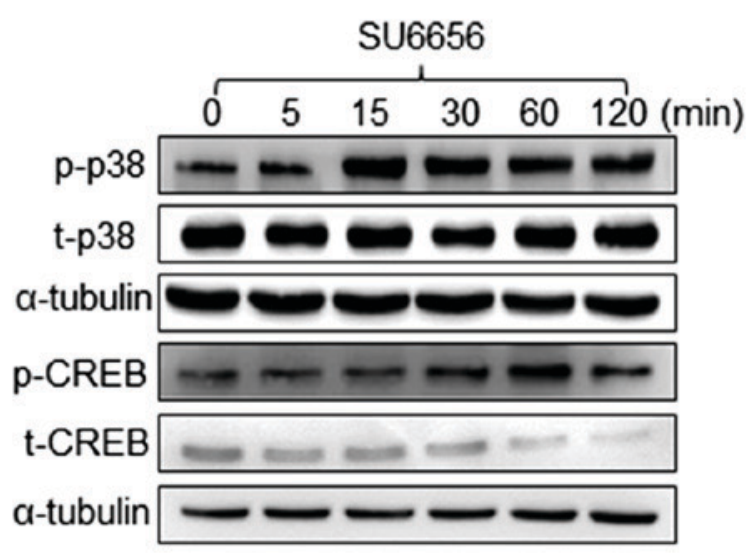

B

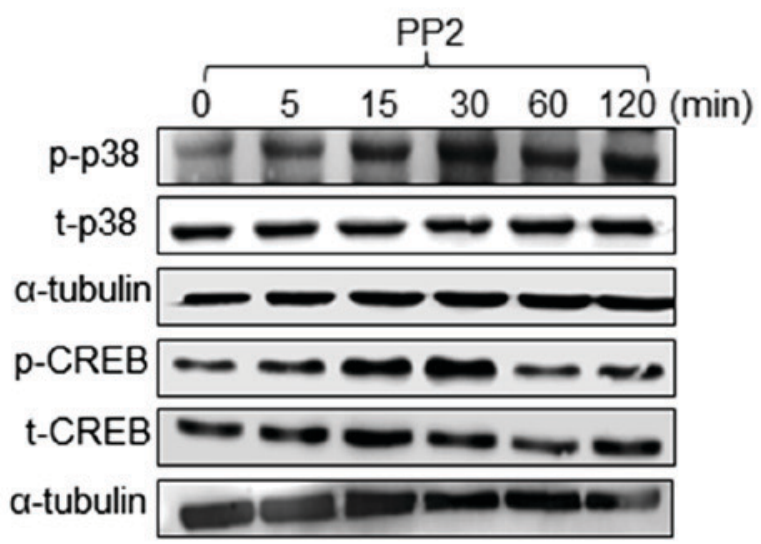

C

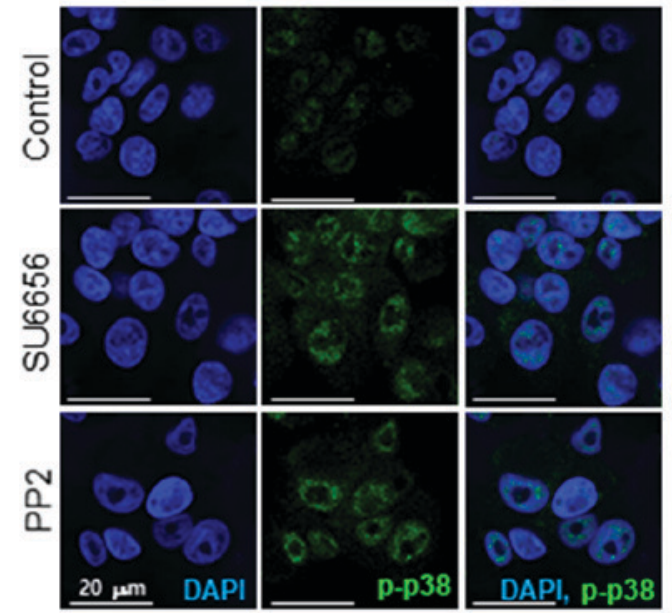

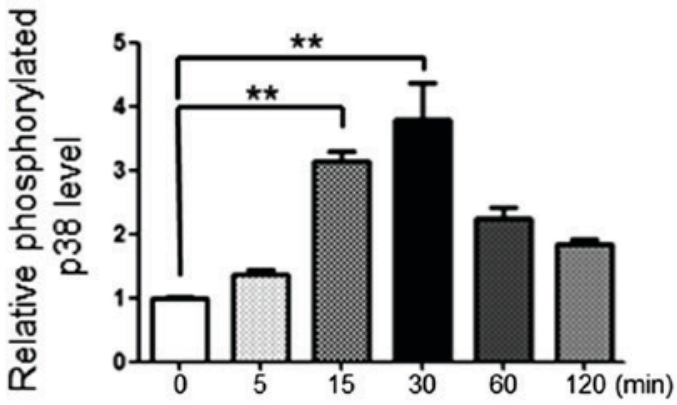
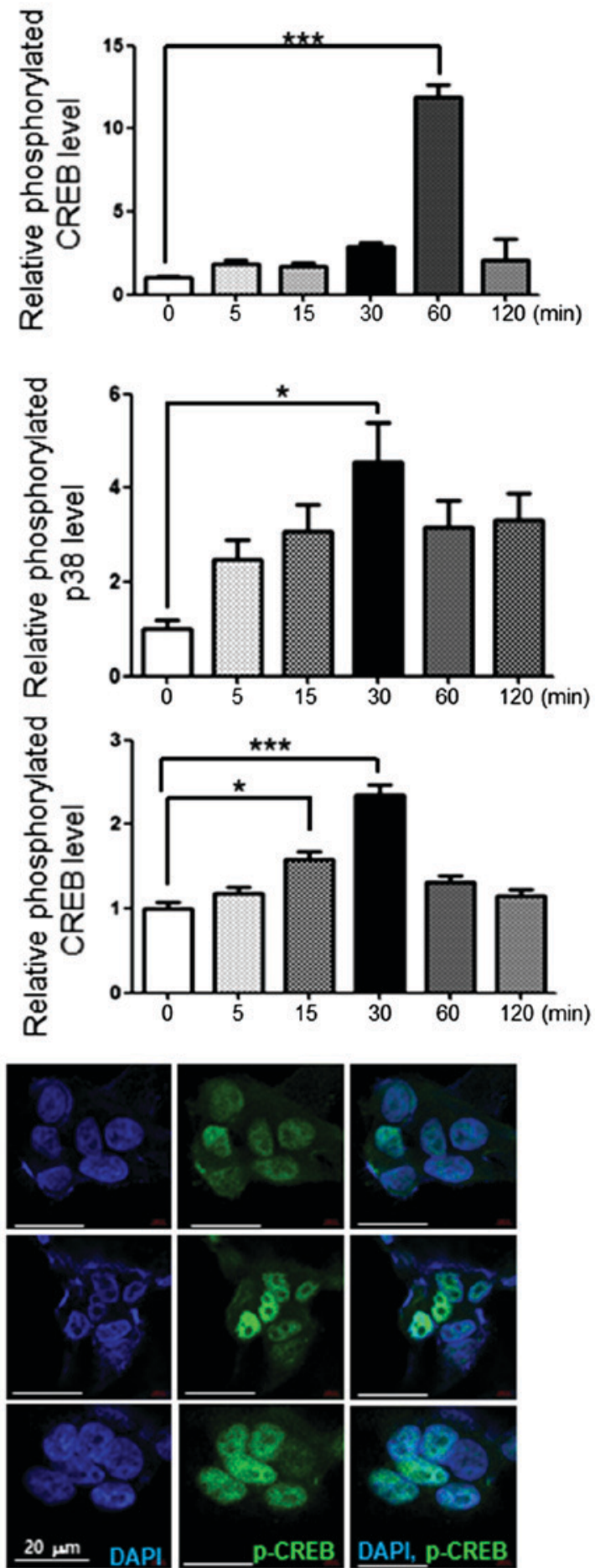

Figure 5. Src inhibition activates the p38 or CREB pathways. (A) Increased phosphorylation of p38 or CREB by the Src inhibitor SU6656 (1 $\mu$ M) was determined by western blotting. (B) Increased phosphorylation of p38 or CREB by the Src inhibitor PP2 $(1 \mu \mathrm{M})$ was revealed by western blotting. (C) Increased expression of p-p38 or p-CREB by SU6656 $(1 \mu \mathrm{M})$ or PP2 $(1 \mu \mathrm{M})$ was determined by immunofluorescence. Scale bars, $20 \mu \mathrm{m}$. Data are presented as the mean \pm standard deviation $(\mathrm{n}=3)$. ${ }^{*} \mathrm{P}<0.05,{ }^{* * *} \mathrm{P}<0.01$ and ${ }^{* * * *} \mathrm{P}<0.001$, as indicated. $\mathrm{p}$-Src, phosphorylated Src; t-Src, total Src; CREB, cyclic adenosine monophosphate response element binding. 

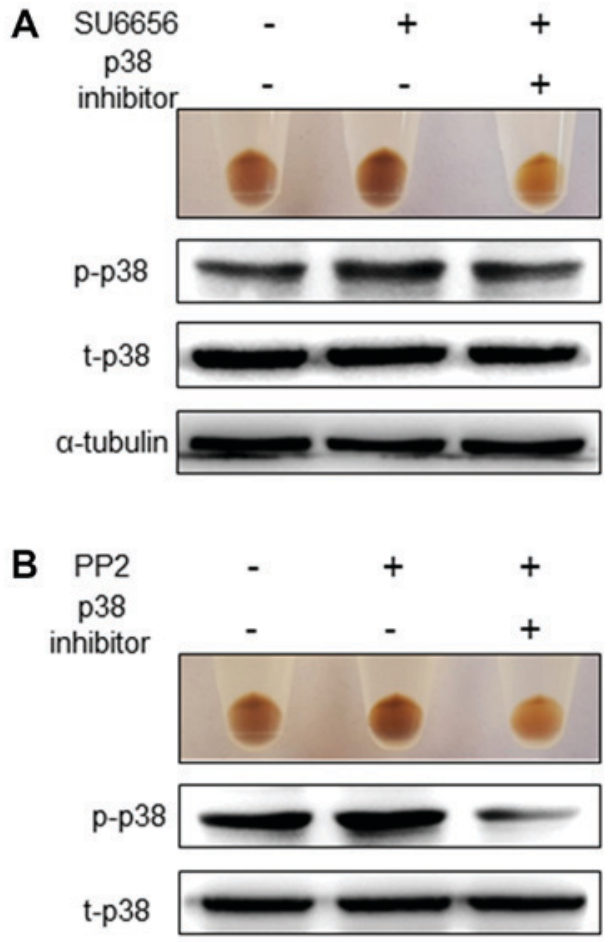

a-tubulin

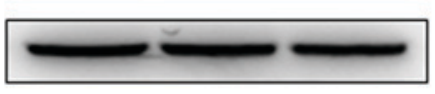

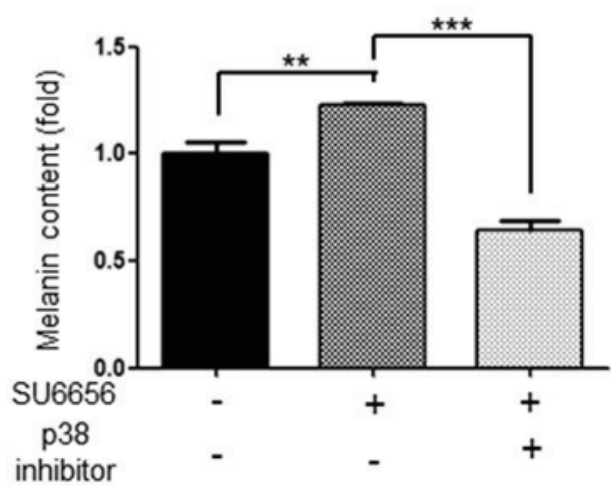

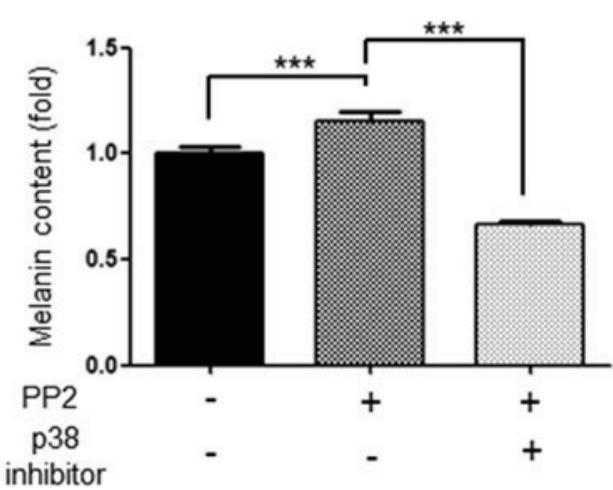

Figure 6. Induced melanogenesis by Src inhibitors is inhibited by the p38 inhibitor. The pigmentation and melanin contents of G361 cells induced by (A) SU6656 $(1 \mu \mathrm{M})$ or (B) PP2 $(1 \mu \mathrm{M})$ were inhibited by the p38 inhibitor SB203580 $(20 \mu \mathrm{M})$. p-Src; phosphorylated Src, t-Src; total Src. Data are presented as the mean \pm standard deviation $(\mathrm{n}=3) .{ }^{* * *} \mathrm{P}<0.01$ and ${ }^{* * *} \mathrm{P}<0.001$, as indicated. $\mathrm{p}-\mathrm{Src}$, phosphorylated Src; t-Src, total Src.

H-89 $(1 \mu \mathrm{M})$, a PKA pathway inhibitor, significantly attenuated the increased melanogenesis induced by SU6656 and PP2. In addition, activation of CREB, which was increased by Src inhibitors, was also markedly decreased (Fig. 7A and B).

\section{Discussion}

c-Kit is known to be expressed in melanocytes and is associated with melanocyte proliferation, melanocyte migration and melanogenesis in response to $\operatorname{SCF}(20,21)$. c-kit is an RTK, as well as an epidermal growth factor receptor, a fibroblast growth factor receptor and a vascular endothelial growth factor receptor. It not only serves a role in cell survival, proliferation and differentiation but also is closely associated with several types of cancer, such as gastrointestinal stromal tumors, testicular seminoma, melanoma and acute myeloid leukemia $(20,22)$. Therefore, RTK inhibitors, also known as c-Kit inhibitors, including imatinib, sorafenib, sunitinib and dasatinib, are now being used as anticancer drugs, even though they are not specific for c-Kit only $(20,22,23)$. According to reports on the side effects of RTK inhibitors with regard to pigmentation, there have been conflicting reports of the pigmentary changes with unknown pathogenesis. Some cases have suggested that hypopigmentation occurs as an adverse effect of patients taking c-Kit inhibitors including imatinib (23-26). By contrast, there have also been reports that have described hyperpigmentation caused by chemotherapy with c-Kit inhibitors (27-29). Therefore, to determine the effect of c-Kit inhibitors on melanogenesis in G361 cells, c-Kit inhibitors such as dasatinib and nilotinib (both at $0.1 \mathrm{M}$ ) were evaluated in the present study. The results revealed that dasatinib and nilotinib (both at $0.1 \mathrm{M}$ ) increased melanin production (data not shown). In addition, dasatinib upregulated the mRNA expression levels of melanogenesis-associated molecules such as MITF, TRP1, TRP2 and tyrosinase in G361 cells (data not shown). However, dasatinib is not as potent as the Src inhibitors SU6656 and PP2 in melanogenesis. Dasatinib inhibited c-Kit, Src and Abl. Therefore, the present study further examined the effect of Src inhibitors on melanogenesis instead of the effect of c-Kit inhibitors.

First, the results demonstrated that the stimulators of melanogenesis, UVB and $\alpha$-MSH, inhibited the phosphorylation of Src in G361 cells. This result suggests that UV- and $\alpha$-MSH-induced pigmentation could be mediated via c-Src inhibition. Src inhibition by the chemical inhibitors SU6656 and PP2 induced melanogenesis in G361 cells and upregulated the mRNA expression levels of the melanogenesis-associated molecules MITF, TRP1, TRP2 and tyrosinase. Src inhibition by siRNA knockdown in G361 cells also induced melanogenesis and upregulated the mRNA expression levels of melanogenesis-associated genes. The p38 MAPK and PKA signaling pathways, which serve a key role in melanogenesis, were examined for Src-mediated pigmentary regulation. Src inhibition by SU6656 or PP2 induced the phosphorylation of p38 and CREB, as determined by western blotting, and increased the expression levels of p-p38 and p-CREB, as revealed by immunofluorescence. In addition, the pigmentation and melanin contents of G361 cells when treated with Src inhibitors 

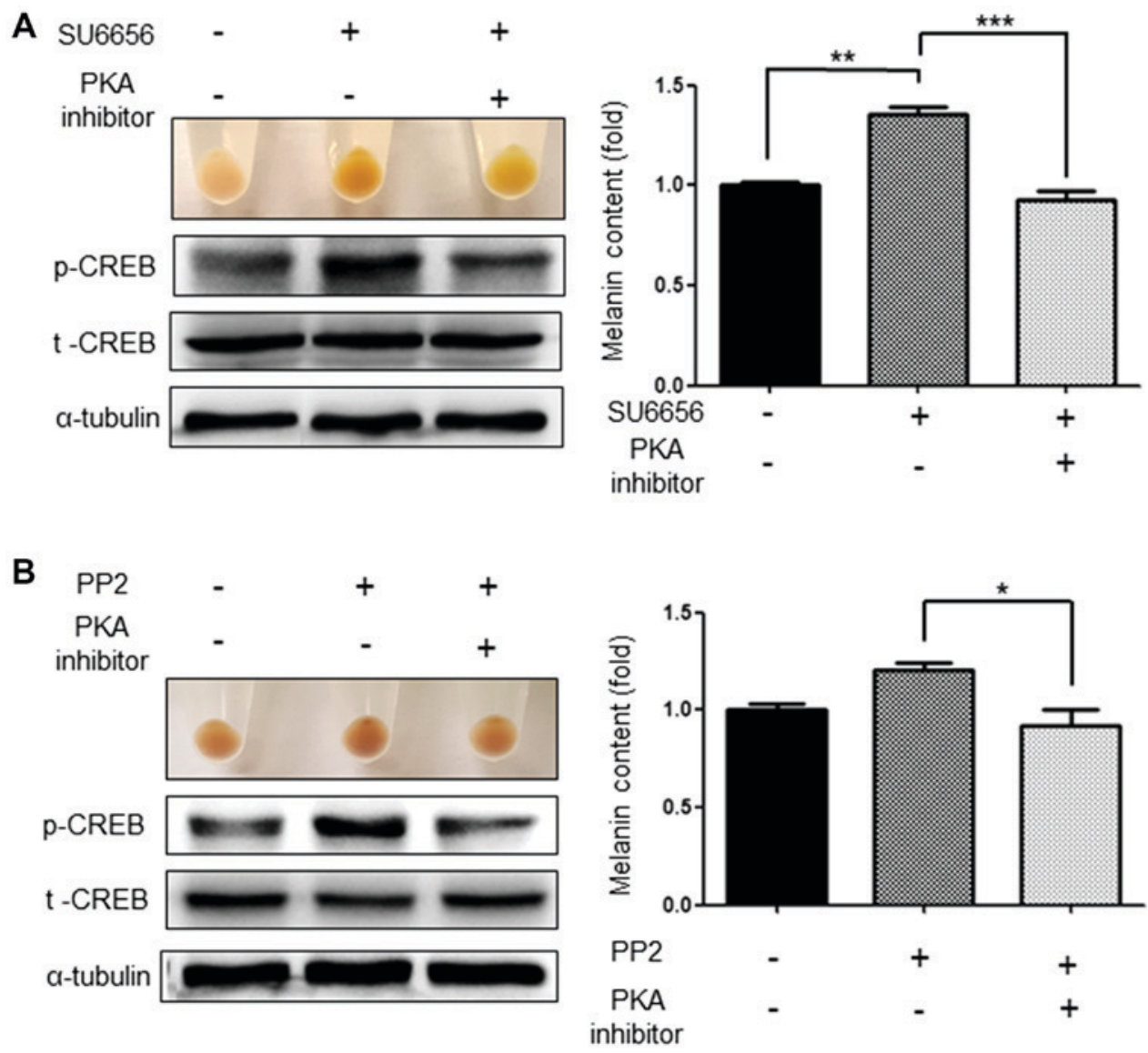

Figure 7. Induced melanogenesis by Src inhibitors is inhibited by the PKA inhibitor. Induced pigmentation and melanin contents by (A) SU6656 ( $1 \mu \mathrm{M})$ or (B) PP2 $(1 \mu \mathrm{M})$ were inhibited by PKA inhibitor $(\mathrm{H}-89,1 \mu \mathrm{M})$. Data are presented as the mean \pm standard deviation $(\mathrm{n}=3)$. ${ }^{*} \mathrm{P}<0.05,{ }^{* * *} \mathrm{P}<0.01$ and ${ }^{* * * *} \mathrm{P}<0.001$, as indicated. p-Src, phosphorylated Src; t-Src, total Src; PKA, protein kinase A.

were significantly inhibited by the p38 and CREB inhibitors. Collectively, these results indicate that Src inhibition induced melanogenesis via the p38 MAPK and PKA signaling pathways in G361 cells. These data are also supported by a previous study that indicated that Src inhibition increased p-p38 expression levels (30). Additionally, the suppression of c-Src activity by PP1 and SU6656 stimulated muscle differentiation via p38 MAPK activation (31). Dasatinib, a c-Kit inhibitor, also exerted an antileukemic effect via the activation of the p38 MAPK signaling pathways (32). Although there is little to no evidence on whether Src inhibitors affect CREB phosphorylation, it is reasonable to assume that $\mathrm{p} 38$ activation can activate the phosphorylation of CREB, which is known to be a downstream signal of p38 during UV-induced melanogenesis.

The activation of c-Src increases the proliferation, survival and invasion of cancer cells, and Src phosphorylation/activation is involved in $50 \%$ of colon, liver, breast and pancreatic tumors (33). Therefore, a number of tyrosine kinase inhibitors against c-Src, including dasatinib, have been developed for cancer therapy (34). c-Src is a non-receptor tyrosine kinase, but c-Src can be activated by many transmembrane proteins including adhesion receptors, RTKs, G-protein coupled receptors and cytokine receptors (13). Melanocytes possess a variety of receptors, such as melanocortin 1 receptor (MC1R; a type of G-protein coupled receptor) and c-Kit (a type of RTK), and melanin production in melanocytes is regulated through external stimulation to the receptors (35). Therefore, the MC1R and c-Kit signaling pathways in melanocytes may be closely associated with c-Src signaling. Understanding the role of the c-Src pathway in melanocytes is critical for understanding melanocyte physiology, and melanoma development and progression. The results of the present study will also help predict pigmentation side effects when Src inhibitors are used for anticancer therapy and develop novel promising hypopigmentation agents for hyperpigmentary disorders, such as melasma and aging spots. In conclusion, Src inhibition in melanocytes may increase melanogenesis through the p38 and CREB signaling pathways.

\section{Acknowledgements}

Not applicable.

\section{Funding}

The present study was supported by a grant from the National Research Foundation (grant no. NRF2018R1A6A1A03023718) funded by the Korean government.

\section{Availability of data and materials}

The datasets used and/or analyzed during the current study are available from the corresponding author on reasonable request. 


\section{Authors' contributions}

KEK and JHS designed the experiments. KEK developed the methodology and performed the experiments. KEK, NC, SHO, WSK, WS and JHS analyzed the data. KEK and JHS wrote the paper. All authors have read and approved the final manuscript.

\section{Ethics approval and consent to participate}

Not applicable.

\section{Patient consent for publication}

Not applicable.

\section{Competing interests}

The authors declare that they have no competing interests.

\section{References}

1. Lin JY and DE Fisher: Melanocyte biology and skin pigmentation. Nature 445: 843-850, 2007.

2. Yun WJ, Kim EY, Park JE, Jo SY, Bang SH, Chang EJ and Chang SE: Microtubule-associated protein light chain 3 is involved in melanogenesis via regulation of MITF expression in melanocytes. Sci Rep 6: 19914, 2016.

3. Brenner M and Hearing VJ: The protective role of melanin against UV damage in human skin. Photochem Photobiol 84: 539-549, 2008.

4. Fitzpatrick TB and Breathnach AS: The epidermal melanin unit system. Dermatol Wochenschr 147: 481-489, 1963 (In German).

5. Videira IF, Moura DF and Magina S: Mechanisms regulating melanogenesis. An Bras Dermatol 88: 76-83, 2013.

6. Sharov AA, Fessing M, Atoyan R, Sharova TY,Haskell-Luevano C, Weiner L, Funa K, Brissette JL, Gilchrest BA and Botchkarev VA: Bone morphogenetic protein (BMP) signaling controls hair pigmentation by means of cross-talk with the melanocortin receptor-1 pathway. Proc Natl Acad Sci USA 102: 93-98, 2005.

7. Halaban R, Rubin JS, Funasaka Y, Cobb M, Boulton T, Faletto D, Rosen E, Chan A, Yoko K and White W: Met and hepatocyte growth factor/scatter factor signal transduction in normal melanocytes and melanoma cells. Oncogene 7: 2195-2206, 1992.

8. Luo D, Chen H, Searles G and Jimbow K: Coordinated mRNA expression of c-Kit with tyrosinase and TRP-1 in melanin pigmentation of normal and malignant human melanocytes and transient activation of tyrosinase by Kit/SCF-R. Melanoma Res 5: 303-309, 1995.

9. Botchkareva NV, Khlgatian M, Longley BJ, Botchkarev VA and Gilchrest BA: SCF/c-kit signaling is required for cyclic regeneration of the hair pigmentation unit. FASEB J 15: 645-658, 2001

10. Katz M, Amit I and Yarden Y: Regulation of MAPKs by growth factors and receptor tyrosine kinases. Biochim Biophys Acta 1773: 1161-1176, 2007.

11. Wellbrock C and Arozarena I: Microphthalmia-associated transcription factor in melanoma development and MAP-kinase pathway targeted therapy. Pigment Cell Melanoma Res 28: 390-406, 2015.

12. Zwick E, Bange J and Ullrich A: Receptor tyrosine kinase signalling as a target for cancer intervention strategies. Endocr Relat Cancer 8: 161-173, 2001.

13. Hubbard SR and Miller WT: Receptor tyrosine kinases: Mechanisms of activation and signaling. Curr Opin Cell Biol 19: 117-123, 2007.

14. Wheeler DL, Iida M and Dunn EF: The role of Src in solid tumors. Oncologist 4: 667-678, 2009.

15. Park J, Chung H, Bang SH, Han AR, Seo EK, Chang SE, Kang DH and Oh ES: (E)-4-(3,4-Dimethoxyphenyl) but-3-en-1-ol enhances melanogenesis through increasing upstream stimulating factor-1-mediated tyrosinase expression. PLoS One 10: e0141988, 2015.

16. Livak KJ and Schmittgen TD: Analysis of relative gene expression data using real-time quantitative PCR and the 2(-Delta Delta C(T)) method. Methods 25: 402-408, 2001
17. Lee KE, Lee SK, Jung SE, Lee Zh and Kim JW: Functional splicing assay of DSPP mutations in hereditary dentin defects. Oral Dis 17: 690-695, 2011

18. Hennessy A, Oh C, Diffey B, Wakamatsu K, Ito S and Rees J: Eumelanin and pheomelanin concentrations in human epidermis before and after UVB irradiation. Pigment Cell Res 18: 220-223, 2005.

19. Niwano T, Terazawa S, Nakajima $\mathrm{H}$ and Imokawa G: The stem cell factor-stimulated melanogenesis in human melanocytes can be abrogated by interrupting the phosphorylation of MSK1: Evidence for involvement of the p38/MSK1/CREB/MITF axis. Arch Dermatol Res 10: 187-196, 2018.

20. Tatro JB, Atkins M, Mier JW, Hardarson S, Wolfe H, Smith T, Entwistle ML and Reichlin S: Melanotropin receptors demonstrated in situ in human melanoma. J Clin Invest 85: 1825-1832, 1990.

21. Thody AJ,Hunt G, Donatien PD and Todd C: Human melanocytes express functional melanocyte-stimulating hormone receptors. Ann NY Acad Sci 680: 381-390, 1993.

22. Hocker TL, Singh MK and Tsao H: Melanoma genetics and therapeutic approaches in the 21st century: Moving from the benchside to the bedside. J Invest Dermatol 128: 2575-2595, 2008.

23. Buscà R, Bertolotto $\mathrm{C}$, Ortonne $\mathrm{JP}$ and Ballotti R: Inhibition of the phosphatidylinositol 3-kinase/p70(S6)-kinase pathway induces B16 melanoma cell differentiation. J Biol Chem 271: 31824-31830, 1996.

24. Cheli Y, Ohanna M, Ballotti R and Bertolotto C: Fifteen-year quest for microphthalmia-associated transcription factor target genes. Pigment Cell Melanoma Res 23: 27-40, 2010.

25. Kobayashi T, Urabe K, Winder A, Jiménez-Cervantes C, Imokawa G, Brewington T, Solano F, García-Borrón JC and Hearing VJ: Tyrosinase related protein 1 (TRP1) functions as a DHICA oxidase in melanin biosynthesis. EMBO J 13: 5818-5825, 1994.

26. Ohguchi K, Akao Y and Nozawa Y: Involvement of calpain in melanogenesis of mouse B16 melanoma cells. Mol Cell Biochem 275: 103-107, 2005.

27. de Melo Maia B, Lavorato-Rocha AM, Rodrigues IS, Baiocchi G, Cestari FM, Stiepcich MM, Chinen LT, Carvalho KC, Soares FA and Rocha RM: Prognostic significance of c-KIT in vulvar cancer: Bringing this molecular marker from bench to bedside. J Transl Med 10: 150, 2012.

28. Marech I, Gadaleta CD and Ranieri G: Possible prognostic and therapeutic significance of $\mathrm{c}-\mathrm{K}$ it expression, mast cell count and microvessel density in renal cell carcinoma. Int J Mol Sci 15: 13060-13076, 2014.

29. Yavuz AS, Lipsky PE, Yavuz S, Metcalfe DD and Akin C: Evidence for the involvement of a hematopoietic progenitor cell in systemic mastocytosis from single-cell analysis of mutations in the c-kit gene. Blood 100: 661-665, 2002.

30. Mora Vidal R, Regufe da Mota S, Hayden A, Markham H, Douglas J, Packham G and Crabb SJ: Epidermal growth factor receptor family inhibition identifies p38 Mitogen-activated protein kinase as a potential therapeutic target in bladder cancer. Urology 112: 225.e1-225.e7, 2018.

31. Lim MJ, Seo YH, Choi KJ, Cho CH, Kim BS, Kim YH, Lee J, Lee H, Jung CY, Ha J, et al: Suppression of c-Src activity stimulates muscle differentiation via p38 MAPK activation. Arch Biochem Biophys 465: 197-208, 2007.

32. Pan C, Olsen JV, Daub H and Mann M: Global effects of kinase inhibitors on signaling networks revealed by quantitative phosphoproteomics. Mol Cell Proteomics 8: 2796-2808, 2009.

33. Liu W, Kovacevic Z, Peng Z, Jin R, Wang P, Yue F, Zheng M, Huang ML, Jansson PJ, Richardson V, et al: The molecular effect of metastasis suppressors on Src signaling and tumorigenesis: new therapeutic targets. Oncotarget 6: 35522-35541, 2015.

34. Johnson FM, Saigal B, Talpaz M and Donato NJ: Dasatinib (BMS-354825) tyrosine kinase inhibitor suppresses invasion and induces cell cycle arrest and apoptosis of head and neck squamous cell carcinoma and non-small cell lung cancer cells. Clin Cancer Res 11: 6924-6932, 2005.

35. Carlson JA, Linette GP, Aplin A, Ng B and Slominski A: Melanocyte receptors: Clinical implications and therapeutic relevance. Dermatol Clin 25: 541-ix, 2007.

This work is licensed under a Creative Commons Attribution-NonCommercial-NoDerivatives 4.0 International (CC BY-NC-ND 4.0) License. 